\title{
Detection of ALK fusion transcripts in FFPE lung cancer samples by NanoString technology
}

\author{
Adriane F. Evangelista ${ }^{1}$, Maicon F. Zanon ${ }^{1}$, Adriana Cruvinel Carloni ${ }^{1}$, Flávia E. de Paula', Mariana Andozia Morini' \\ Maressa Ferreira-Neto', Iberê Cauduro Soares ${ }^{2}$, Jose Elias Miziara ${ }^{3}$, Pedro de Marchi', \\ Cristovam Scapulatempo-Neto ${ }^{1,2}$ and Rui M. Reis ${ }^{1,5,6^{*}}$
}

\begin{abstract}
Background: ALK-rearranged lung cancers exhibit specific pathologic and clinical features and are responsive to anti-ALK therapies. Therefore, the detection of ALK-rearrangement is fundamental for personalized lung cancer therapy. Recently, new molecular techniques, such as NanoString nCounter, have been developed to detect ALK fusions with more accuracy and sensitivity.

Methods: In the present study, we intended to validate a NanoString nCounter ALK-fusion panel in routine biopsies of FFPE lung cancer patients. A total of 43 samples were analyzed, 13 ALK-positive and 30 ALK-negative, as previously detected by FISH and/or immunohistochemistry.

Results: The NanoString panel detected the presence of the EML4-ALK, KIF5B-ALK and TFG-ALK fusion variants. We observed that all the 13 ALK-positive cases exhibited genetic aberrations by the NanoString methodology. Namely, six cases (46.15\%) presented EML-ALK variant 1, two (15.38\%) presented EML-ALK variant 2, two (15.38\%) presented EML-ALK variant 3a, and three (23.07\%) exhibited no variant but presented unbalanced expression between $5^{\prime} / 3^{\prime}$ exons, similar to other positive samples. Importantly, for all these analyses, the initial input of RNA was $100 \mathrm{ng}$, and some cases displayed poor RNA quality measurements.
\end{abstract}

Conclusions: In this study, we reported the great utility of NanoString technology in the assessment of ALK fusions in routine lung biopsies of FFPE specimens.

Keywords: ALK, ALK fusions, NanoString, FFPE

\section{Background}

The anaplastic lymphoma kinase (ALK) gene is located in the $2 \mathrm{p} 23$ chromosome region and codifies a tyrosine kinase receptor of the insulin receptor family [1]. Genetic aberrations in the $A L K$ gene were first described in anaplastic large cell lymphoma by Morris and colleagues [1] as part of an oncogenic fusion protein resulting from the translocation between chromosomes 2 and $5(\mathrm{t}[2 ; 5]$ [p23;q35]) (NPM-ALK - Nucleophosmin- anaplastic lymphoma kinase). In 2007, Soda and colleagues concluded that

\footnotetext{
* Correspondence: ruireis.hcb@gmail.com

1 Molecular Oncology Research Center, Barretos Cancer Hospital, Rua Antenor

Duarte Villela, 1331, Barretos CEP 14784-400, São Paulo, Brazil

${ }^{5}$ Life and Health Sciences Research Institute (ICVS), Health Sciences School,

University of Minho, Braga 4710-057, Portugal

Full list of author information is available at the end of the article
}

the $A L K$ gene fusion was also an oncogenic driver of non-small cell lung cancer (NSCLCs) [2]. In these tumors, the most common fusion partner, the EML4 (Echinoderm microtubule-associated protein-like 4) gene, results from a small inversion within the short arm of chromosome 2, and it is found in approximately $3-7 \%$ of NSCLCs $[2,3]$. Other partners encoding KIF5B-ALK (<1\%), TFG-ALK (2\%), KLC1-ALK $(<5 \%), P T P N 3-A L K(<1 \%)$ and in rare events and isolated cases the aberrant proteins HIP1-ALK, TPR$A L K, S T R N-A L K$, and $A 2 M-A L K$ have also been described in cancers [4-6]. The aberrant $A L K$ fusions promote dimerization domains that are ligand independent, with consequent constitutive kinase activity and malignant transformation [5]. 
$A L K$-rearranged lung cancers exhibit specific clinical and pathologic features [7]. They are associated with younger patients ( $<50$ years), non-smokers, prevalent mucinous histology, signet ring morphology in some cases, and EGFR and KRAS wild-type cases [3, 8, 9]. Importantly, $A L K$ rearrangement predicts the clinical response to Crizotinib (Xalkori', Pfizer), an oral MET/ALK inhibitor, ATP-competitive inhibitors of the ALK tyrosine kinase, Ceritinib (Zykadia ${ }^{\text {Tu }}$, Novartis) and Alectinib (Alecensa ${ }^{\circ}$, Roche), second-generation $A L K$ inhibitors, and lorlatinib (PF-06463922) [10, 11].

Consequently, accurate molecular methodologies that detect and quantify $A L K$ fusions and their variants have been developed for therapeutic selection. Recently, an $A L K$ fusion panel was designed and tested using NanoString technology, which is considered a more sensitive method since it performs direct molecule counting, avoiding the bias associated with amplification [12-14]. The $A L K$ panel was created using two strategies. The first group of eight probes over several exons was designed to detect an unbalanced expression. The second set of probes was designed in the breakpoint of the known variants of EML4-ALK, KIF5B-ALK and TFG$A L K$. For this strategy, a pair of adjacent probes (35$50 \mathrm{bp}$ each) were used, the first (biotin-capture probe) complementary to the partner gene, and the other (barcoded reporter probe) to the $A L K$ gene at exon 20 [13].

In the present study, we reported the feasibility of the NanoString $A L K$ fusion panel to detect the $A L K$ fusion transcripts in formalin-fixed paraffin-embedded (FFPE) samples of lung adenocarcinoma in a Brazilian population. We also evaluated whether a lower quantity (up to $100 \mathrm{ng}$ ) of RNA could be used in a routine diagnostic setting of tumor biopsies.

\section{Methods \\ Material}

In the present study, we performed a retrospective evaluation of a convenience series of 43 lung carcinoma samples from the Pathology Department of Barretos Cancer Hospital (Brazil) between 2012 and 2015 (Additional file 1: Table S1). These cases were selected based on their previous evaluation for $A L K$ rearrangement by immunohistochemistry and/or fluorescence in situ hybridization (FISH) in our Department of Pathology. The cases were also assessed for EGFR and KRAS mutation status.

As controls, we used the lung adenocarcinoma cell lines H2228 (ALK-positive) and CALU3 (ALK-negative) (ATCC, Manassas, VA). Cell monolayers were grown in Dulbecco's modified Eagle's medium (DMEM) (Gibco) supplemented with $10 \%$ fetal bovine serum (Gibco) and $1 \%$ penicillin-streptomycin (Gibco). The cells were incubated in a $5 \% \mathrm{CO}_{2}$ environment at $37^{\circ} \mathrm{C}$.
This study was approved by the Barretos Cancer Hospital Ethical Review Committee ((\#630/2012). Due the retrospective nature of the study, the Local Ethical Review Committee waived the need for patients written informed consent.

\section{DNA isolation}

Serial 5- $\mu \mathrm{m}$ unstained sections of formalin-fixed paraffinembedded blocks were cut, and one adjacent hematoxylin and eosin-stained (H\&E) section was taken for pathologist identification and selection of the tumor tissue. DNA was macrodissected from 1 unstained section from each specimen as previously described $[15,16]$. Briefly, tissues were deparaffinized at $80{ }^{\circ} \mathrm{C}$ and serially washed with xylene and ethanol (100, 70 and 50\%). Selected areas of the tumor or precursor lesions were macrodissected using a sterile needle $\left(18 \mathrm{G} \times 1^{1} /^{2}\right)(\mathrm{BD}$, Curitiba, Brazil) and carefully collected into a microtube. DNA was extracted using a QIAamp DNA Micro Kit (Qiagen, Hilden, Germany) following the manufacturer's instructions. DNA quantity and quality was evaluated by Nanodrop 2000 (Thermo Scientific, Wilmington, USA). DNA samples were diluted to a final concentration of $50 \mathrm{ng} / \mu \mathrm{l}$ and stored at $-20{ }^{\circ} \mathrm{C}$ for further molecular analysis.

\section{Mutational analysis of EGFR and KRAS}

The hotspot regions of the oncogenes EGFR (exons 18, 19, 20 and 21) and KRAS (codons 12/13) were analyzed by polymerase chain reaction (PCR), followed by direct sequencing, as previously described [17]. Briefly, PCR was performed in a final volume of $15 \mu \mathrm{l}$, with $50 \mathrm{ng}$ of DNA and $10 \mu \mathrm{M}$ of forward and reverse primers, using $7.5 \mu \mathrm{l}$ of the HotStar master mix (Qiagen, Hilden, Germany) according to the protocol proposed by the manufacturer, with the following cycling parameters: $96^{\circ} \mathrm{C}$ for $15 \mathrm{~min}$, followed by 40 cycles of $96{ }^{\circ} \mathrm{C}$ for $45 \mathrm{~s}, 58^{\circ} \mathrm{C}$ for $45 \mathrm{~s}$ (EGFR) or $56.5^{\circ} \mathrm{C}$ for $45 \mathrm{~s}(K R A S), 72{ }^{\circ} \mathrm{C}$ for $45 \mathrm{~s}$ and $72{ }^{\circ} \mathrm{C}$ for $10 \mathrm{~min}$ in a thermocycler (Veriti, Applied Biosystems, Carlsbad, USA). Primer sequences were previously described [15]. The PCR products were evaluated by electrophoresis in agarose gel and further purified using ExoSAP-it (Affymetrix), followed by cycle sequencing carried out using a BigDye Terminator v3.1 Cycle Sequencing kit (Applied Biosystems, Foster City, CA) with an initial denaturation at $97{ }^{\circ} \mathrm{C}$ for $3 \mathrm{~min}$, followed by 28 cycles of $96{ }^{\circ} \mathrm{C}$ for $10 \mathrm{~s}, 50{ }^{\circ} \mathrm{C}$ for $5 \mathrm{~s}$, and $60{ }^{\circ} \mathrm{C}$ for $4 \mathrm{~min}$. Sequencing products were purified using BigDye Xterminator (Applied Biosystems) and analyzed on a 3500 DNA Analyzer with a ABI capillary electrophoresis system (Applied Biosystems). Sequences were analyzed using the SeqScape software package (Applied Biosystems).

\section{Fluorescence in situ hybridization (FISH) Assay}

The presence of $A L K$ gene rearrangement was determined using fluorescence in situ hybridization (FISH) 
assay using the commercially available ALK probe (Vysis LSI ALK Dual Color, Break Apart Rearrangement Probe; Abbott Molecular, Abbott Park, IL) as described elsewhere [18]. The lung adenocarcinoma cell lines H2228 (ALK-positive) and CALU3 (ALK-negative) were used as the positive and negative control, respectively. Paraffinembedded sections (5 $\mu \mathrm{m}$ thick) were initially incubated at $60{ }^{\circ} \mathrm{C}$, deparaffinized with xylene and dehydrated in $100 \%$ ethanol. Tissue sections were then transferred to a $0.2 \mathrm{~N} \mathrm{HCL}$ solution and incubated at $80{ }^{\circ} \mathrm{C}$ with $10 \mathrm{mM}$ citrate at $\mathrm{pH} 6.4$ and $1 \mathrm{mM}$ EDTA at $\mathrm{pH}$ 8.0. Slides were enzymatically treated with pepsin in $0.01 \mathrm{~N} \mathrm{HCL}$ and washed once with water. Five microliters of the ALK probe was applied to the tumor tissue, and a subsequent denaturation step was performed at $83{ }^{\circ} \mathrm{C}$ for $10 \mathrm{~min}$. Hybridization was carried out for $22 \mathrm{~h}$ in a humidified chamber at $37{ }^{\circ} \mathrm{C}$. Tissue sections were washed in $0.3 \%$ Igepal/2x SSC at $63{ }^{\circ} \mathrm{C}$ for $4 \mathrm{~min}$, and then washed with $2 x$ SSC at room temperature. Nuclei were counterstained with DAPI (4,6-diamidino-2-phenylindole) and analyzed using an Eclipse 50i microscope with fluorescence (Nikon Instruments). From each sample, 100 tumor nuclei per slide were analyzed, and the standard score of $>=15 \%$ was used to determine the presence of ALK rearrangement, as previously reported $[18,19]$. For the analysis, the software FISHView 6.0 (Applied Spectral Imaging) was used.

\section{Immunohistochemistry (IHC)}

The presence of ALK overexpression was assessed by immunohistochemistry (IHC) staining using $4-\mu \mathrm{m}$-thick sections. Ganglion cells present in sections of the appendix were used as positive controls, and in negative controls, the primary antibody was omitted. Immunohistochemical reactions were performed at Ventana Benchmark XT using the Ventana ALK (D5F3) CDx assay (Ventana, Tucson, AZ, clone 790-4796) according to the manufacturer. In brief, slides of the NSCLC tumor were subjected to deparaffinization using EZ Prep (Ventana, Tucson, AZ) and antigen retrieval was performed using Cell Conditioning 1 (Ventana, Tucson, AZ). Tissue sections were then incubated with anti-ALK antibody (clone D5F3, Ventana, Tucson, AZ) for $20 \mathrm{~min}$. The OptiView DAB IHC Detection Kit (Ventana, Tucson, AZ) and OptiView Amplification Kit (Ventana, Tucson, AZ) were used according to the manufacturer's recommendations for the visualization of the bound primary antibody. The ALK stain was considered positive if at least one cell presented strong dark brown cytoplasmic staining as stated in the kit's manual as previously described [20].

\section{RNA isolation}

Tumor cell content ( $>60 \%)$ was assessed based on H\&Estained slides, and RNA was isolated from two to four sections (10 $\mu \mathrm{m}$ thick) using a RecoverALL total Nucleic Acid Isolation kit (Life Technologies) according to the manufacturer's instructions. Briefly, the process is divided into four steps: (i) an initial preparation that includes slide scraping, deparaffinization with xylene and $100 \%$ ethanol dehydration; (ii) protease digestion; (iii) nucleic acid isolation using the filter cartridge, followed by washing; and (iv) DNase digestion with additional washes and elution. RNA concentration was assessed using both the Nanodrop 1000 spectrophotometer (NanoDrop Products, Thermo Scientific, Wilmington, DE) and Qubit (Life Technologies).

\section{NanoString nCounter Assay}

The custom ALK panel was carried out using the NanoString nCounter Elements ${ }^{\mathrm{m}}$ protocol per the manufacturer's instructions. All procedures regarding sample preparation, hybridization, detection and scanning were performed as recommended by NanoString Technologies (NanoString, Seattle, WA). The custom probes (A and B) were designed by IDT (IDT Technologies, Coralville, USA) and contained $35-50 \mathrm{bp}$ each, as previously described by Lira and co-authors [13]. Probes were diluted to a final concentration of $0.6 \mathrm{nM}$ (probe A) and $3.0 \mathrm{nM}$ (probe B) to create the $30 \mathrm{X}$ working probe pools. The total amount of up to 100 ng RNA was used. RNA was hybridized with probe pools, hybridization buffer and TagSet reagents in a total volume of $30 \mu \mathrm{l}$ and incubated at $67^{\circ} \mathrm{C}$ for $20 \mathrm{~h}$. Samples were then loaded to the automated nCounter Sample Prep Station (NanoString Technologies, Seattle, WA), which performed the purification steps and cartridge preparation. Finally, the cartridges containing immobilized and aligned reporter complexes were transferred to a nCounter Digital Analyzer (NanoString Technologies), and expression data were subsequently generated using the high-resolution setting, which takes 600 images per sample.

\section{Data analysis}

The reporter counts were collected using NanoString's nSolver analysis software v2.5 and normalized as previously described by Lira and co-authors [13]. Briefly, raw probe counts were normalized by positive reaction controls to a panel of three housekeeping genes (GUSB1, OAZ1 and $P O L R 2 A$ ). Additionally, a detection $3^{\prime} / 5$ ' score was defined by the ratio between geometric mean of 3'-probes and average of 5'-probes, with a 2.0 threshold for positivity, as reported by Lira and co-workers [13]. The statisticalmathematical R software v.3.2.3 (https://www.r-project.org) was used for this analysis and graphical construction.

\section{Results}

All 43 cases analyzed were previously evaluated by immunohistochemistry (Fig. 1a), which showed the presence of ALK positivity in 13/43 (30.2\%) of cases. In a 


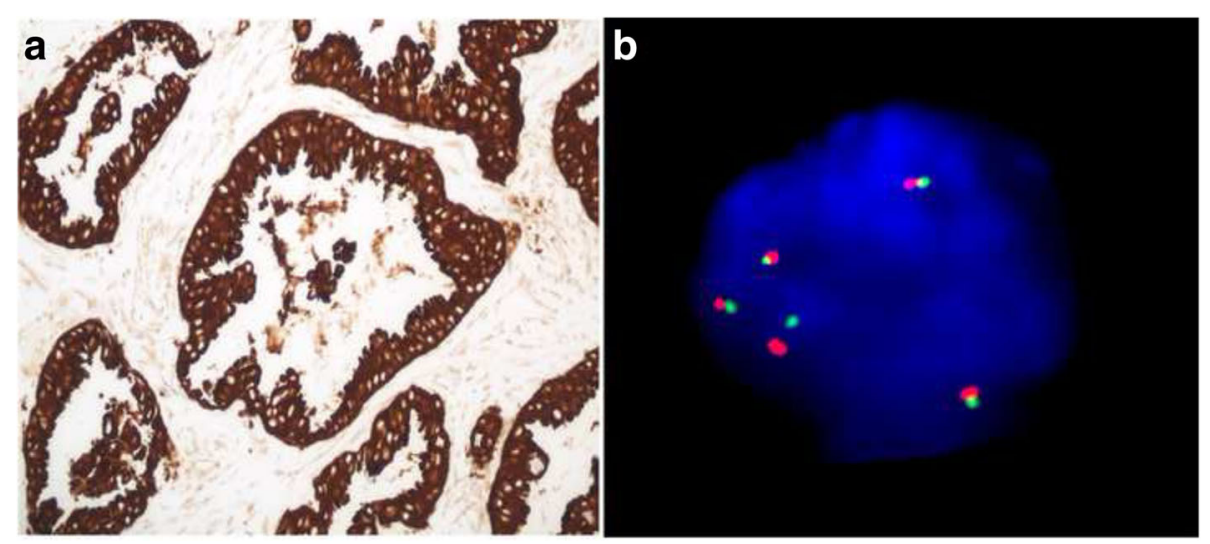

Fig. 1 ALK positivity represented by $I H C$ (a) and the interphase nucleus with the presence of ALK rearrangement by FISH (score $>15 \%)$ (b)

subset of cases $(n=24)$, we also performed FISH assays (Fig. 1b). In these 24 cases, we found $100 \%$ concordance between the FISH and immunohistochemistry methodologies.

Concerning the NanoString assay, we first performed a pilot analysis to determine whether a distinct initial RNA quantity would yield equivalent results. Using the H2228 (ALK-positive) cell line, we compared the use of $500 \mathrm{ng}$ of RNA as reported by Lira and co-authors [13] and 100 ng of RNA as recently suggested by NanoString. We reported Pearson correlations of 0.99 for 5 '-probes and 0.93 for 3'-probes, with counts of EML-ALK V3a of 54.68 (100 ng) and 49.40 (500 ng), respectively (Fig. 2).

We further analyzed 43 cases, and of those, three were excluded due to signal detection flags by NanoString nSolver software. These three cases were from biopsies and two of them yielded a total RNA quantity below $100 \mathrm{ng}$ (Additional file 1: Table S1). The 3'/5' score and heatmap of normalized expression values of validated cases $(n=40)$ are shown in Fig. 3a and b, respectively. The concordance between the NanoString, immunohistochemistry and FISH methodologies was $100 \%$.

Among the $13 A L K$-positive cases, the following variants were identified: six (46.15\%) exhibited $E M L-A L K 1$, two (15.38\%) exhibited EML-ALK 2, two (15.38\%) exhibited $E M L A L K-V 3 a$, and three (23.07\%) exhibited no variant. However, in these cases, the increase in counts in 3'-probes was evident, with average 3'/5' scores of approximately 20 and normalized expression values of approximately 100 (case 1 to 13) (Fig. $3 a$ and b). The variant $E M L-A L K-V 3 a$ presented lower expression than the others (case_3 and case_13), accounting for 57.61 and 82.67 of normalized NanoString counts, respectively. These normalized values were similar to those observed for the H2228 cell line, which also exhibited this variant (Fig. 3b). No differences in $K I F 5 B-A L K$ variants were observed in the cases analyzed. TFG-ALK presented normalized values of approximately 40 in two cases (Fig. 3b). However, this was not considered relevant since the same patients presented higher counts of $E M L-A L K 1$. Moreover, similar normalized values of TFG-ALK were also observed in $A L K$-negative patients (Fig. $3 \mathrm{~b}$ ).

\section{Discussion}

Aberrant $A L K$ fusions were recently identified in a subset of lung cancer patients, resulting in the constitutive activation of MEK/ERK and PI3K pathways, with consequent up-regulation of cell survival and proliferation mechanisms [9, 21]. Importantly, its detection had a paramount clinical impact, as it was a predictive biomarker of the therapeutic response $[9,21]$. Recently, Lira and co-authors [13] design a panel to detect $A L K$ fusion rearrangements by the NanoString assay. The authors analyzed $34 A L K$-positive and $33 A L K$-negative FFPE non-small cell lung cancer samples, obtaining $93 \%$ concordance with FISH and 98\% concordance with immunohistochemistry [13]. For these analyses, the authors used 500 ng of input RNA, which is an important value. In the diagnostic procedures for lung cancer pathology, the availability of sufficient quantities of biopsy tissue ultimately limit the application of these methodologies.

In the present study, we sought to implement the NanoString panel of $A L K$ fusion detection for lung cancer patients and to optimize its applicability in biopsies using up to $100 \mathrm{ng}$ of RNA. These small amounts are in line with the recent protocols of NanoString for Elements. We analyzed the biopsy specimens of 43 patients diagnosed with lung cancer, mainly non-small cell lung cancer. Following RNA isolation, we observed the heterogeneity of RNA quality and quantity, representing the reality of a routine setting. Despite the low quantities of RNA used and their variable quality, only three cases were flagged (3 $A L K$-negative), representing just $~ 7 \%$ failure. The improvement of the panel, including the detection of the clearly positive samples (according to 5'/3' unbalanced probes) but detecting no variant, can also be 


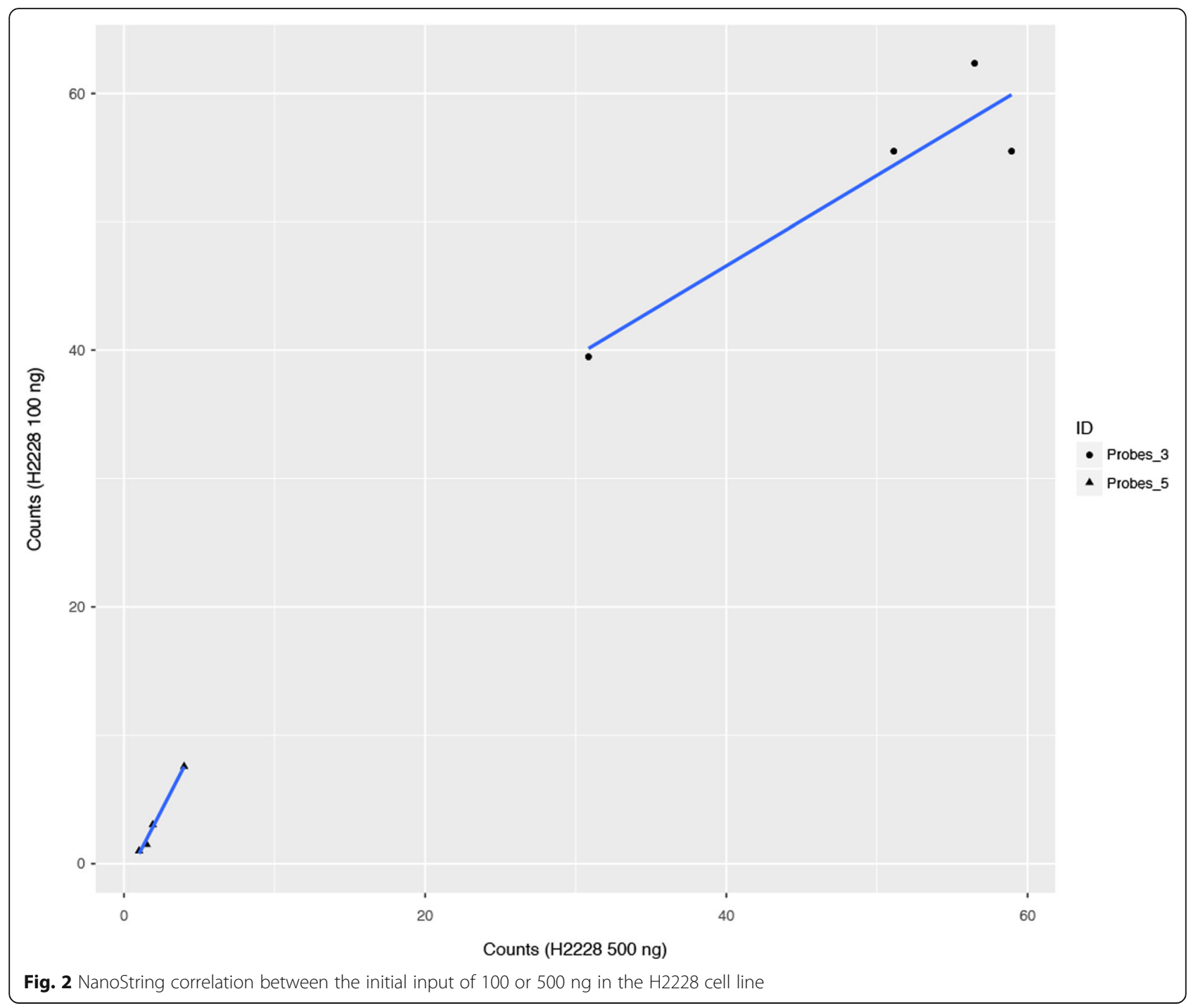

of potential use. Our NanoString results were further compared with FISH and immunohistochemistry analysis and showed a full concordance of methodologies. Of the 40 cases with reliable results, 13 exhibited $A L K$ gene fusions. $E M L-A L K 1$ was the most common, being present in approximately half of them. These results are in agreement with previous studies $[4,5]$.

It has been reported that the different variants can exhibit distinct sensitivity to Crizotinib [22, 23]. Among the methodologies currently available for $A L K$ fusion detection, only NanoString and next-generation sequencing (NGS) can perform such differentiation (Table 1). Recently, Rogers and co-authors compared the technics of FISH, NanoString, Agena LungFusion panel and ThermoFisher NGS [24]. The authors found a great concordance between all techniques, and reported that NanoString requires more RNA input, yet, is less prone to false-positives [24]. Moreover, Ali and co-authors [25] suggested that NGS could be especially useful for detecting ALK rearrangements, including those with other partners. One of the major advantages of NGS is the potential for multiplex testing, but it has some disadvantages, such as the higher cost, and it requires more effort for analysis [26] (Table 1).

Furthermore, in Table 1, we address all current ALK rearrangement methodologies and explore their advantages and disadvantages. As shown in Table 1, NanoString represents an interesting option considering its hands-on time, quantitative precision, robustness in samples with extremely poor quality (since it is unbiased toward amplification and sequence errors) and ease of analysis. This technique allows for the detection of a high number of molecules similarly to microarrays, yet with a sensitivity for qPCR [14]. Moreover, NanoString is very flexible for the construction of custom panels, and it yields highly confident, accurate and reproductive results in low quality 


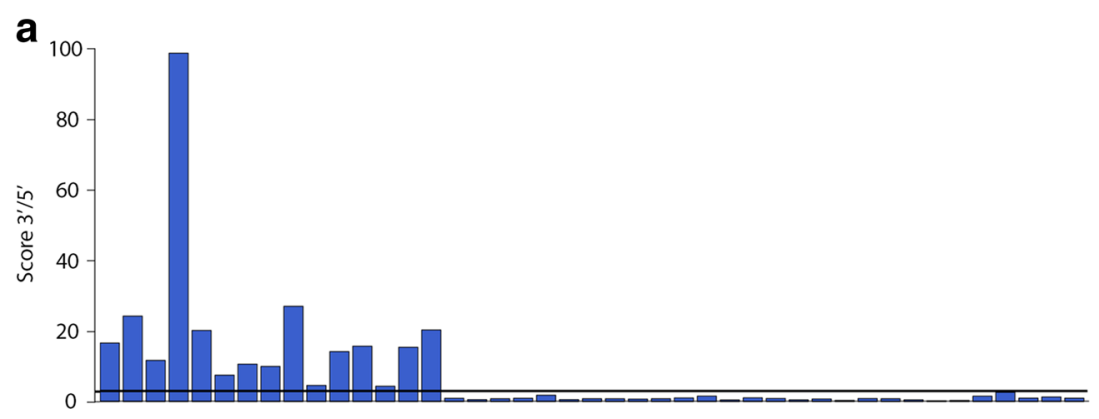

b

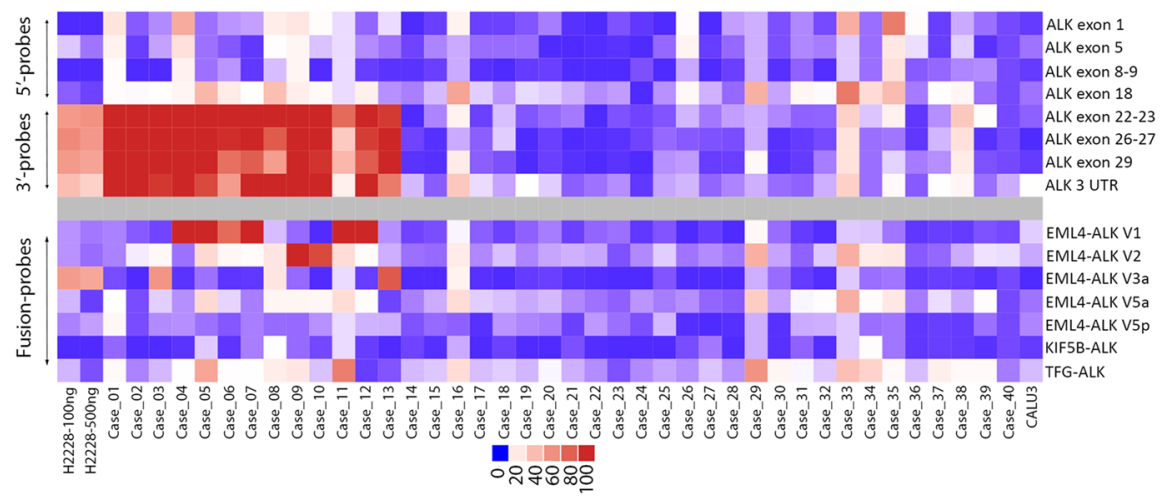

Fig. 3 Barplot representing the ALK $3^{\prime} / 5^{\prime}$ score of each sample with the indication of the threshold line of positivity (a); Heatmap showing the expression of 5'-ALK probes (exon 1 to exon 18) and 5'-ALK probes (exon 22 to $3^{\prime}-U T R$ ) and ALK variants (EML-ALK, KIF5B-ALK and TGF-ALK) (b)

and quantity RNA from FFPE tissues [14]. However, it is important to consider that this new technology has some limitations, i) the high cost for hardware and software, mainly for the process of acquisition and maintenance of the devices, which has been limited in Latin America (Table 1); and ii) considering the fusion assay, the detection is mainly detected by a previously defined $3^{\prime} / 5^{\prime}$ score, which is not totally defined and it is not possible to detect new fusion partners. In this regard, further studies are necessary to expand the panel intending to include new partners and to develop a defined analysis pipeline for fusion detection, with specific thresholds for fusion probes to avoid bias of interpretation.

Finally, in the future, with the novel standardizations and improvements in chemistry to improve the sensitivity at low input when compared with other technics [24]

Table 1 Comparison of FISH, IHC, qRT-PCR, NGS and NanoString regarding costs, procedural difficulty and resolution

\begin{tabular}{|c|c|c|c|c|c|c|}
\hline & & $\mathrm{FISH}$ & $\mathrm{IHC}$ & qRT-PCR & NGS & NanoString \\
\hline \multirow[t]{2}{*}{ Costs } & Overal reagents costs & $* / * *$ & $* * *$ & $* * / * * *$ & * & $* * / * * *$ \\
\hline & Hardware \& software costs & $* *$ & $* * *$ & $* *$ & * & * \\
\hline \multirow[t]{6}{*}{ Procedural difficulty } & RNA input required & NA & NA & * & $* * *$ & ** \\
\hline & $\begin{array}{l}\text { Poor quality } \\
\text { samples }\end{array}$ & $* / * *$ & $* * * * *$ & * & $* / * *$ & $* * / * *$ \\
\hline & Hands on time & $* / * *$ & $* / * *$ & $* *$ & $* / * *$ & $* * *$ \\
\hline & Run time and results analysis & $* *$ & $* *$ & $* *$ & * & $* * / * *$ \\
\hline & Interpretation of results & $* / * *$ & $* / * *$ & $* *$ & $* * *$ & ** \\
\hline & Throughput & * & $* / * *$ & $* *$ & $* * *$ & $* * / * *$ \\
\hline \multirow[t]{3}{*}{ Resolution } & Accuracy at low concentrations & NA & NA & ** & $* / * *$ & $* * *$ \\
\hline & Quantitative precision & $* / * *$ & */** & $* *$ & $* * *$ & $* * *$ \\
\hline & Variants detection & * & * & $* *$ & $* * *$ & $* * / * * *$ \\
\hline
\end{tabular}


(Table 1), NanoString methodology can be used to address special issues, such as the detection of ALK rearrangements in CTCs [27].

\section{Conclusions}

In this study, we report the utility of NanoString technology in the assessment of $A L K$ fusions in FFPE specimens from routine lung biopsies.

\section{Additional file}

Additional file 1: Table S1. Association of ALK fusion and the main clinicopathological and molecular features. Summary of the major clinico-pathological characteristics of patients and RNA quality information and ALK, EGFR and KRAS status. (XLSX $14 \mathrm{~kb})$

\section{Abbreviations}

A2M-ALK: alpha-2-macroglobulin and anaplastic lymphoma kinase; ALK: Anaplastic lymphoma kinase; DAPI: 4',6-Diamidino-2-phenylindole; DMEM: Dulbecco's modified Eagle's medium; EML4-ALK: Echinoderm microtubule-associated protein-like 4 and anaplastic lymphoma kinase; FFPE: Formalin-fixed paraffin-embedded; FISH: Fluorescence in situ hybridization; H\&E: Hematoxylin and eosin-stained; HIP1-ALK: Huntingtin interacting protein 1 and anaplastic lymphoma kinase; IHC: Immunohistochemistry (IHC); KIF5B-ALK: Kinesin family member 5B and anaplastic lymphoma kinase; KLC1-ALK: Kinesin light chain 1 and anaplastic lymphoma kinase; NPMALK: Nucleophosmin-anaplastic lymphoma kinase; NSCLC: Non-small cell lung cancer; PTPN3-ALK: Protein tyrosine phosphatase, non-receptor type 3 and anaplastic lymphoma kinase; STRN-ALK: Striatin and anaplastic lymphoma kinase; TFG-ALK: TRKfused gene and anaplastic lymphoma kinase; TPR-ALK: Translocated promoter region, nuclear basket protein and anaplastic lymphoma kinase

\section{Acknowledgments}

We would like to thank Ana Carolina de Carvalho for helping with technical issues in RNA isolation.

\section{Funding}

This study was partially funded by FINEP (MCTI/FINEP/MS/SCTIE/DECIT), Brazil. BIOPLAT $(1302 / 13)$

\section{Availability of data and materials}

Data requests can be sent to Dr. Rui Reis.

\section{Authors' contributions}

RMR was responsible for the initial idea and obtaining funding. AFE, MFZ, PdM and ACC were responsible for collecting data, sample preparation and NanoString experiments. FEP was responsible for EGFR and KRAS genotyping. MAM, JEM and CS were the pathologists involved in the selection of samples. MFZ, MF and ICS were responsible for FISH and IHC experiments. AFE analyzed the data and wrote the original paper in English. RMR made revisions, edited the use of language, and ultimately wrote the final version of the manuscript, which was reviewed by all the authors. All authors read and approved the final manuscript.

\section{Competing interests}

The authors declare that they have no competing interests.

\section{Consent for publication}

Not applicable.

\section{Ethics approval and consent to participate}

This study was approved by the Barretos Cancer Hospital Ethical Review Committee ((\#630/2012). Due the retrospective nature of the study, the Local Ethical Review Committee waived the need for patients written informed consent.

\section{Publisher's Note}

Springer Nature remains neutral with regard to jurisdictional claims in published maps and institutional affiliations.

\section{Author details}

${ }^{1}$ Molecular Oncology Research Center, Barretos Cancer Hospital, Rua Antenor Duarte Villela, 1331, Barretos CEP 14784-400, São Paulo, Brazil. 'Department of Pathology, Barretos Cancer Hospital, Rua Antenor Duarte Villela 1331 Barretos CEP 14784-400, São Paulo, Brazil. ²Department of Thoracic Surgery, Barretos Cancer Hospital, Rua Antenor Duarte Villela 1331, Barretos CEP 14784-400, São Paulo, Brazil. ${ }^{4}$ Department of Clinical Oncology, Barretos Cancer Hospital, Rua Antenor Duarte Villela 1331, Barretos CEP 14784-400, Sao Paulo, Brazil. ' Life and Health Sciences Research Institute (ICVS), Health Sciences School, University of Minho, Braga 4710-057, Portugal. ' ICVS/3B's-PT Government Associate Laboratory, Braga/Guimarães 4710-057, Portugal.

Received: 25 March 2017 Accepted: 19 May 2017

Published online: 26 May 2017

\section{References}

1. Morris SW, Kirstein MN, Valentine MB, Dittmer KG, Shapiro DN, Saltman DL, et al. Fusion of a kinase gene, ALK, to a nucleolar protein gene, NPM, in non-Hodgkin's lymphoma. Science. 1994;263:1281-4

2. Soda M, Choi YL, Enomoto M, Takada S, Yamashita Y, Ishikawa S, et al. Identification of the transforming EML4-ALK fusion gene in non-small-cell lung cancer. Nature. 2007:448:561-6.

3. Wong DW-S, Leung EL-H, So KK-T, Tam IY-S, Sihoe AD-L, Cheng L-C, et al. The EML4-ALK fusion gene is involved in various histologic types of lung cancers from nonsmokers with wild-type EGFR and KRAS. Cancer. 2009;115:1723-33.

4. Takeuchi K, Choi YL, Togashi Y, Soda M, Hatano S, Inamura K, et al. KIF5BALK, a novel fusion oncokinase identified by an immunohistochemistrybased diagnostic system for ALK-positive lung cancer. Clin Cancer Res. 2009:15:3143-9.

5. Rikova K, Guo A, Zeng Q, Possemato A, Yu J, Haack H, et al. Global Survey of Phosphotyrosine Signaling Identifies Oncogenic Kinases in Lung Cancer. Cell. 2007;131:1190-203.

6. Roskoski R. Anaplastic lymphoma kinase (ALK): structure, oncogenic activation, and pharmacological inhibition. Pharmacol Res. 2013;68:68-94.

7. Mossé YP, Wood A, Maris JM. Inhibition of ALK signaling for cancer therapy. Clin Cancer Res. 2009;15:5609-14.

8. Gaughan EM, Costa DB. Genotype-driven therapies for non-small cell lung cancer: focus on EGFR, KRAS and ALK gene abnormalities. Ther Adv Med Oncol. 2011;3:113-25.

9. Shaw AT, Yeap BY, Mino-Kenudson M, Digumarthy SR, Costa DB, Heist RS, et al. Clinical features and outcome of patients with non-small-cell lung cancer who harbor EML4-ALK. J Clin Oncol. 2009:27:4247-53.

10. McKeage K. Alectinib: A Review of Its Use in Advanced ALK-Rearranged Non-Small Cell Lung Cancer. Drugs. 2014:75:75-82.

11. Wu J, Savooji J, Liu D. Second- and third-generation ALK inhibitors for nonsmall cell lung cancer. J Hematol Oncol. 2016:9:19.

12. Jung S-H, Sohn I. Statistical Issues in the Design and Analysis of nCounter Projects. Cancer Inform. 2014;13:35-43.

13. Lira ME, Kim TM, Huang D, Deng S, Koh Y, Jang B, et al. Multiplexed gene expression and fusion transcript analysis to detect ALK fusions in lung cancer. J Mol Diagn. 2013;15:51-61.

14. Kulkarni MM. Digital multiplexed gene expression analysis using the NanoString nCounter system. Curr Protoc Mol Biol. 2011;25:Unit25B.10.

15. Yamane LS, Scapulatempo-Neto C, Alvarenga L, Oliveira CZ, Berardinelli GN, Almodova $\mathrm{E}$, et al. KRAS and BRAF mutations and MSI status in precursor lesions of colorectal cancer detected by colonoscopy. Oncol Rep. 2014;32:1419-26.

16. Becker AP, Scapulatempo-Neto C, Carloni AC, Paulino A, Sheren J, Aisner DL, et al. KIAA1549: BRAF Gene Fusion and FGFR1 Hotspot Mutations Are Prognostic Factors in Pilocytic Astrocytomas. J Neuropathol Exp Neurol. 2015;74:743-54.

17. Reis-Filho JS, Pinheiro C, Lambros MBK, Milanezi F, Carvalho S, Savage K, et al. EGFR amplification and lack of activating mutations in metaplastic breast carcinomas. J Pathol. 2006;209:445-53.

18. Camidge DR, Kono SA, Flacco A, Tan A-C, Doebele RC, Zhou Q, et al. Optimizing the detection of lung cancer patients harboring anaplastic lymphoma kinase (ALK) gene rearrangements potentially suitable for ALK inhibitor treatment. Clin Cancer Res. 2010;16:5581-90. 
19. Kwak EL, Bang Y-J, Camidge DR, Shaw AT, Solomon B, Maki RG, et al. Anaplastic lymphoma kinase inhibition in non-small-cell lung cancer. N Engl J Med. 2010;363:1693-703.

20. Wynes MW, Sholl LM, Dietel M, Schuuring E, Tsao MS, Yatabe Y, et al. An international interpretation study using the ALK IHC antibody D5F3 and a sensitive detection kit demonstrates high concordance between ALK IHC and ALK FISH and between evaluators. J Thorac Oncol. 2014;9:631-8.

21. Wilson FH, Johannessen CM, Piccioni F, Tamayo P, Kim JW, Van Allen EM, et al. A functional landscape of resistance to ALK inhibition in lung cancer. Cancer Cell. 2015;27:397-408.

22. Heuckmann JM, Balke-Want H, Malchers F, Peifer M, Sos ML, Koker M, et al. Differential protein stability and ALK inhibitor sensitivity of EML4-ALK fusion variants. Clin Cancer Res. 2012;18:4682-90

23. Crystal AS, Shaw AT. Variants on a theme: a biomarker of crizotinib response in ALK-positive non-small cell lung cancer? Clin Cancer Res. 2012;18:4479-81.

24. Rogers T-M, Arnau GM, Ryland GL, Huang S, Lira ME, Emmanuel Y, et al. Multiplexed transcriptome analysis to detect ALK, ROS1 and RET rearrangements in lung cancer. Sci Rep. 2017;7:42259.

25. Ali SM, Hensing T, Schrock AB, Allen J, Sanford E, Gowen K, et al. Comprehensive Genomic Profiling Identifies a Subset of CrizotinibResponsive ALK-Rearranged Non-Small Cell Lung Cancer Not Detected by Fluorescence In Situ Hybridization. Oncologist. 2016;21:762-70.

26. Dagogo-Jack I, Shaw AT. Screening for ALK Rearrangements in Lung Cancer: Time for a New Generation of Diagnostics? Oncologist. 2016;21:662-3.

27. Cesano A. nCounter $\left({ }^{\oplus}\right)$ PanCancer Immune Profiling Panel (NanoString Technologies, Inc., Seattle, WA). J Immunother Cancer. 2015;3:42.

\section{Submit your next manuscript to BioMed Central} and we will help you at every step:

- We accept pre-submission inquiries

- Our selector tool helps you to find the most relevant journal

- We provide round the clock customer support

- Convenient online submission

- Thorough peer review

- Inclusion in PubMed and all major indexing services

- Maximum visibility for your research

Submit your manuscript at www.biomedcentral.com/submit 